\title{
ANOTACIONES SOBRE LA OBRA Y VIDA DE JOSÉ MARÍA DÍAZ MORENO: SU FRUCTÍFERA PRODUCCIÓN TRAS SU JUBILACIÓN
}

\author{
Autora: Cristina Guzmán Pérez \\ cguzman@comillas.edu \\ Universidad Pontificia Comillas
}

\section{Resumen}

En este breve artículo se realiza una breve semblanza biográfica del Padre Díaz Moreno S.J., a modo de homenaje, recordando sus diferentes responsabilidades y, en particular, su obra como profesor universitario. A continuación, se realiza una recopilación de toda su bibliografía, que alcanza las 250 obras publicadas entre libros, capítulos de libro y artículos de revista.

Palabras clave: Derecho canónico; derecho matrimonial; derecho de familia; derecho eclesiástico del Estado.

Notes on the work and life of Jose María Díaz Moreno: his fruitful production after his retirement

\footnotetext{
Abstract

In this short article, a brief biographical semblance of Father Díaz Moreno S.J. is made, as a tribute, remembering his different responsibilities and, in particular, his 
work as University Professor. Below, there is a compilation of all his bibliography, which reaches 250 publications between books, book chapters and review articles.

Key words: Canon law; Matrimonial law; familiar law; ecclesiastical law of State.

Fecha de recepción: 31/10/2019.

Fecha de aceptación: 03/11/2019.

\section{BREVE SEMBLANZA DEL PADRE DÍAZ MORENO}

El curriculum vitae del P José María Diaz Moreno, S.J. publicado en la página web de la Universidad Pontificia Comillas ${ }^{1}$, elaborado por el propio profesor, es el siguiente:

"José María Díaz Moreno, S. J., extremeño, de Villafranca de los Barros (27-XII-26). Desde 1944 es jesuita y desde 1958 sacerdote. Licenciado en Filosofía y Teología y Doctor en Derecho Canónico por la Universidad Gregoriana de Roma. Medalla de oro a su Tesis doctoral. Durante 56 años ha sido profesor de Derecho Canónico y Teología moral en las Facultades de Derecho (ICADE), de Teología y Derecho Canónico de la Universidad Pontificia Comillas en Madrid y de Derecho Canónico de la Pontificia Universidad de Salamanca.

Rector de ICAI-ICADE durante siete años y colaborador del Nuncio Dadaglio durante diez años, como miembro de la Comisión Permanente en la elaboración y negociación de los Acuerdos vigentes entre la S. Sede y el Estado Español.

Durante muchos años ha colaborado en Cursos de Formación Permanente del Clero, de Preparación al Matrimonio, y en la Escuela de Formadores de Religiosos en Salamanca.

Es, además, testigo directo del tránsito entre el Código de 1917 y el de 1983 y de la experiencia eclesial que ha supuesto este cambio.

Es miembro correspondiente de la Real Academia de Legislación y Jurisprudencia. Ha participado, con Ponencias, en numerosos Congresos y Simposios de su especialidad y ha centrado su atención, como publicista de temas canónicos, en la Libertad Religiosa y Derecho Público de la Iglesia, en la Parroquia y Curia Diocesana, en la relación fe-sacramento en el matrimonio canónico, en la pastoral de uniones irregulares y en los derechos humanos en la Iglesia.

Durante todos estos años ha conjugado su tarea universitaria con la atención y orientación a matrimonios y familias en situaciones difíciles.

\footnotetext{
${ }^{1}$ https://www.canonico.comillas.edu/images/Documentos K2/congreso cic/cic curr Moreno.pdf (última consulta 21/10/2019).
} 
El padre Díaz Moreno es uno de los principales impulsores de la Asociación Española de Canonistas, de la que ha sido vicepresidente y, por decisión unánime de los socios, el 5 de abril de 1918 fue nombrado Socio de Honor "en agradecimiento a su magisterio y calidad humana que tan profunda huella ha dejado en la Asociación.”

Una vez transcrito este modesto y brevísimo curriculum, es de justicia a la vez que para mí un gran honor, ofrecer una semblanza personal de este insigne canonista y mejor persona.

El P. José María Diaz Moreno, S.J. es extremeño, si bien muy unido a Sevilla a donde acudía cada semana santa con su padre para participar fervientemente en las procesiones y donde aprendió que pese a haber muchas vírgenes con distintos nombres, solo una era la madre de Dios. Quedó sin madre muy niño, con apenas cuatro años, y fue criado por sus abuelos paternos y su hermana mayor, Mercedes, a la que siempre ha querido como una madre. Su niñez y adolescencia transcurrió en el colegio de los jesuitas de Villafranca de los Barros. Con la cercanía y formación que allí recibió, con apenas 16 años y medio, ingresó en el noviciado de Aranjuez. Él siempre cuenta que no le permitieron que se enamorara y que la forma que tuvieron sus maestros y preceptores de cortar una incipiente ilusión fue convencerle para que ingresara en tan temprana edad en el noviciado porque, como jesuita, podría salvar de la condenación a muchas almas. En el noviciado de Aranjuez hizo sus votos un 11 de junio de 1946, ante la imagen de una virgen que ahora está en la capilla de la residencia de Alcalá de Henares, a la que tiene una especial devoción.

Tras sus estudios de Filosofía en Madrid y de Teología en Granada, años éstos muy fructíferos espiritual y culturalmente -donde visitaba con asiduidad la Alhambra y el patio de los arrayanes, según él mismo reconoce-, completó sus estudios universitarios con la licenciatura y, más tarde, doctorado, en Derecho Canónico, en la Universidad Gregoriana de Roma. José María tenía vocación de misionero, o si no, hubiera preferido estudiar la licenciatura en Historia, pero aceptó con su voto de obediencia cursar los estudios canónicos. Durante los años 1962 a 1964 prestó sus servicios al Padre General de la Compañía en la curia romana. Este destino, como asesor canónico, lo desempeñó con total dedicación, pero no con vocación porque para él no era un trabajo reconfortante.

Desde mediados de los años sesenta, su destino fue ICADE, si bien también enseñaba en la Facultad de Teología (Teología Moral), en Comillas (Santander). En ICADE impartía inicialmente la disciplina de Derecho Canónico en la licenciatura de Derecho, con gran deleite y entusiasmo de los que fuimos sus alumnos. Sus clases, con los ejemplos personalizados en los simpáticos Ticio y Caya, se mantienen en el recuerdo de todos los que disfrutamos su gran capacidad docente siguiendo el estilo ignaciano, con claridad, ingenio, amenidad, sentido del humor, cercanía. Desde entonces aprendí -y apliqué siempre que pude- que las exposiciones tenían que 
ser esquemáticas y que nunca se debía dividir una materia objeto de exposición en más de tres partes y en menos de tres, porque, como él decía, "Julio César dividió la Guerra de las Galias en tres partes”. Más tarde, a partir de la modificación estatal de los planes de estudios universitarios, fue profesor también de la asignatura de Derecho Eclesiástico del Estado en ICADE y de Derecho matrimonial canónico, así como de otras disciplinas en la Facultad de Derecho Canónico de la Universidad. Ha impartido cursos de Formación Permanente del Clero, de Preparación al Matrimonio, seminarios monográficos y cursos de doctorado sobre materias diversas, algunas ellas de cierta aridez, si bien siempre sabía convertirlas en interesantes y amenas. Cada año fue el profesor que mejor calificación obtenía de los alumnos.

También fue Rector de ICAI-ICADE, desde 1967 hasta 1975 y superior de la Comunidad de jesuitas. Esta etapa fue especialmente dura para él, tanto por las secularizaciones de compañeros jesuitas como por las dificultades económicas que conllevaba el desarrollo de la Universidad ${ }^{2}$. Pero como el propio P. Diaz Moreno reconoció en una entrevista, en esos años convulsos de su rectorado su aportación fue dotar a ICAI-ICADE de unos Estatutos que respondieran a la calidad y cualidad universitaria ${ }^{3}$. Esto le mereció la medalla del ICAI impuesta por su sucesor, el Rector P. Ezcurdia.

Poco después de terminar su rectorado, le llamaron como colaborador del Nuncio Dadaglio para, durante diez años, ser miembro de la Comisión Permanente en la elaboración y negociación de los Acuerdos vigentes entre la S. Sede y el Estado Español. Sobre estos años de la transición democrática española y la difícil negociación entre la Iglesia y el Estado para modificar el Concordato de 1953, ha escrito diversos artículos ${ }^{4}$ y dirigido una tesis doctoral ${ }^{5}$, y, además, lo ha contado

\footnotetext{
${ }^{2}$ Sobre estos años, vid. la entrevista que está recogida en 50 años Muchas vidas en un proyecto. ICADE 1960-2010, pp. 85-88.

${ }^{3}$ Vid. Revista ICADE-ASOCIACIÓN. Octubre 2010, p. 29.

${ }^{4}$ Cfr. Díaz Moreno, J. M. (2017). Las relaciones Iglesia-Estado en España, en la segunda mitad del siglo XX. Notas personales, en Moreno Antón, M. (ed.), Sociedad, Derecho y Factor religioso. Estudios en honor del Prof. Isidoro Martín Sánchez (pp. 195-210). Granada; Díaz Moreno, J. M. (2013). Los diez primeros informes sobre la revisión el Concordato de 1953. Contribución a la historia de los Acuerdos vigentes, REDC, 70, 143-158 y en Martínez-Torrón, J., Meseguer, S. \& Palomino, R. (coords.) (2013). Religión, Matrimonio y Derecho, ante el siglo XXI. Estudios en homenaje al Prof. Rafael Navarro-Valls (pp. 187-237); Díaz Moreno, J. M. (2013). Las negociaciones concordatarias y la transición política española. Estudios Eclesiásticos, 88, 936-937; Díaz Moreno, J. M. (2010). Por qué y cómo se hicieron los Acuerdos entre España y la S. Sede, en Caparrós, M. C., Martín, M. M. \& Salido, M. (eds.). XXX años de los Acuerdos entre España y la S. Sede (pp. 21-50). Granada: edit. Comares; Díaz Moreno, J. M. (2006). El proceso de negociación y conclusión de los Acuerdos entre la S. Sede y el Estado español de 1979, en VV. AA. Laicidad Cristiana e identidad cristiana (pp. 13-48). Salamanca; Díaz Moreno, J. M. (2005). Los Acuerdos entre la Santa Sede y el Estado Español de 1979. Revista Moralia, 28, 475-502; Díaz Moreno, J. M. (2001). Las relaciones Iglesia-Estado en la segunda mitad del siglo XX. Datos personales para un balance. Revista XX Siglos 12, 58-77.

${ }^{5}$ La tesis inédita de la Prof. Perez-Agua López, T. Mª . (1998). Del Concordato de 1953 a los Acuerdos Parciales con la Sta. Sede. La renuncia a los privilegios. Historia y significado. Madrid: Universidad Pontificia Comillas, Facultad de Derecho-Icade. Departamento de Derecho Canónico.
} 
con gran amenidad a los alumnos de la Facultad de Derecho de ICADE, después de alcanzada su jubilación, ya cumplidos los 85 años. Soy testigo directo de que sus clases magistrales terminaban con una gran ovación.

Con ocasión de su jubilación en la Universidad de Comillas y de su nombramiento como profesor emérito de la misma, en 1997, cuatro compañeros de la Universidad organizamos y coordinamos la edición de un libro homenaje ${ }^{6}$. El gran maestro no merecía menos.

El inspirador de dicho libro homenaje, el querido y añorado profesor José María Castán Vázquez, ya hizo una semblanza muy cercana y sentida sobre la vida y la obra de José María Díaz Moreno hasta el año 1999. El Prof. Castán, a la vez que agradecía a los 62 colaboradores su participación en esta obra y lamentaba que muchos colegas hubieran quedado fuera de la edición por ser un volumen dedicado al matrimonio, elogiaba la capacidad de estudio, investigación, análisis, comunicación, docencia y pastoralidad de quien ante todo es jesuita y ha seguido a ultranza las enseñanzas de San Ignacio?. La Prof. Pérez-Agua López, recogía, a continuación de esta semblanza y clasificada por materias, la obra y actividad científica y pastoral del Prof. José María Díaz Moreno ${ }^{8}$. Enumeraba 178 obras y 268 ponencias, cursos y conferencias, muchas de ellas publicadas.

El P. José María Díaz Moreno ha cumplido 75 años de jesuita el pasado 11 de junio de 2019. Con ocasión de este aniversario, la Compañía de Jesús, además de agradecerle su dedicación y servicio a la Iglesia, a la Universidad y a la Compañía, organizó una celebración eucarística a la que pudimos asistir los más cercanos a él. Éramos un nutrido número de personas las que queríamos compartir con él estos emotivos momentos. No en balde, el P. José María ha dedicado su vida a todos nosotros -la mayoría alumnos que se convirtieron en amigos-, en todas sus facetas: como sacerdote (bendiciendo el matrimonio de antiguos alumnos, bautizando y dando la primera comunión a sus hijos), como maestro y, a la vez, colega; como amigo; como director (también espiritual), como tío abuelo; como padre espiritual, como abuelo espiritual... Con sus lúcidos 93 años todavía podemos disfrutar de su locuaz ingenio y memoria, así como de sus innumerables anécdotas vividas, entre

\footnotetext{
${ }^{6}$ Castán Vázquez, J. M., Guzmán Pérez, C., Perez-Agua López, T. M. \& Sánchez García, J. M. (coords.) (2000). Hominum causa omne ius constitutum: escritos sobre el matrimonio en homenaje al prof. Dr. José María Díaz Moreno, S. J. Madrid: Universidad Pontificia Comillas.

${ }^{7}$ Cfr. Castán Vázquez, J. M. (2000). La vida y la obra del P. José María Díaz Moreno, S.J., en Castán Vázquez, J. M., Guzmán Pérez, C., Perez-Agua López, T. M. a \& Sánchez García, J. M. (coords.). Hominum causa omne ius constitutum: escritos sobre el matrimonio en homenaje al prof. Dr. José María Díaz Moreno, S.J. (pp. 23-30). Madrid: Universidad Pontificia Comillas.

${ }^{8}$ Pérez-Agua López, T. M.aㅡ (2000). La obra y actividad científica y pastoral del Prof. José María Díaz Moreno. En Castán Vázquez, J. M., Guzmán Pérez, C., Perez-Agua López, T. M. a \& Sánchez Garcia, J. M. (coords.). Hominum causa omne ius constitutum: escritos sobre el matrimonio en homenaje al prof. Dr. José María Díaz Moreno, S.J. (pp. 31-64). Madrid: Universidad Pontificia Comillas.
} 
las que siempre se encuentran referencias a su afición taurina y a las zarzuelas. En fin, nos hizo pasar un rato maravilloso y nos demostró, una vez más, que su generosidad y valía humana supera la de canonista. Yo, en particular, he tenido el privilegio de vivir muy de cerca los años transcurridos desde 1975 y compartir aspectos profesionales, personales e, incluso, sus aficiones a la música clásica, a la Zarzuela y a las corridas de Toros. También en estas aficiones se disfruta y se aprende de su sabiduría.

José María Castán finalizaba su semblanza sobre el P. José María Díaz Moreno, confiando en que la obra fecunda del P. Diaz Moreno, fuera todavía ampliada y enriquecida en años venideros. Y sus deseos se hicieron realidad.

Me corresponde ahora a mí, presentar la recopilación cronológica que el propio P. Diaz Moreno ha realizado y que se recoge en estas líneas, desde 1960 a 2019. Me centro en todo lo investigado y escrito desde su jubilación en la Universidad de Comillas que alcanza la cifra de 92 obras. Él no se jubiló voluntariamente, sino que le jubilaron -como insiste en afirmar- una vez alcanzados los 70 años. Pero continuó investigando, escribiendo e impartiendo docencia en la Universidad Pontificia de Salamanca once años más (Asociaciones, Teología del Derecho Canónico y en el ámbito del Derecho matrimonial, el valor canónico del matrimonio civil), para prestigio de esta Universidad y gozo de los alumnos que allí cursaban sus estudios de Licenciatura en Derecho Canónico.

La producción del P. Diaz Moreno ha continuado siendo muy plural, dentro del ámbito canónico: fieles y asociaciones, curia diocesana, sacramentos, historia, magisterio. No obstante, su mayor atención ha continuado siendo el matrimonio, la familia y el Derecho Público Eclesiástico (relaciones Iglesia y Estado y libertad religiosa). También es abundante su contribución a libros homenaje, de temática plural, en favor de distintos compañeros y/o colegas que se jubilaron o fallecieron.

Todas las materias han sido tratadas desde un profundo estudio doctrinal y desde una visión cercana a la realidad social en la que ha vivido y en la que ha pretendido siempre respetar la doctrina de la Iglesia, pero a la vez, con un espíritu crítico y una cierta esperanza de apertura y cambio ante las nuevas situaciones. Para ello, en sus obras, no duda en ofrecer posibles soluciones ante situaciones conflictivas. Para mí, son de especial atención aquellas publicadas, en esta etapa madura y reflexiva de su vida, que tienen relación con la familia, el matrimonio, la moral sexual y la pastoral matrimonial y familiar. Por mi especial dedicación como abogada matrimonialista, destaco aquellas que se refieren a la transmisión de la fe en la familia, la presencia/ausencia de fe en la recepción de sacramentos, la atención a las uniones de hecho, a los matrimonios dispares o mixtos -cada vez más frecuentes en nuestra sociedad-y a los divorciados vueltos a casar.

En fin, espero que estas líneas introductorias de la bibliografía que a continuación pueden leer, sean un aliciente para que los interesados lectores se acerquen 
y profundicen en toda la producción científica, e incluso divulgativa, del P. Diaz Moreno, porque, aunque no vaya dirigida esta publicación a canonistas, estoy segura de que sí será apreciada por todos los que han sido antiguos alumnos e, incluso, profesores compañeros de la Universidad en la que, no en balde, enseñó durante 56 años. El P. Diaz Moreno, nuestro Dimo, siempre será un modelo a seguir.

\section{BIBLIOGRAFÍA PERSONAL DEL P. JOSÉ MARÍA DÍAZ MORENO, S.J.}

\section{0}

1. La doctrina moral sobre la parvedad de materia in re venerea desde Cayetano hasta S. Alfonso. Archivo Teológico Granadino, 23, 5-138.

\section{5}

2. Principios morales fundamentales de una deontología cristiana de las telecomunicaciones. Madrid.

\section{6}

3. Guiones para el estudio de Teología Moral (IV-V y VI Mandamientos). Apuntes Privados para uso de los alumnos. Madrid: Facultad de Teología. Universidad Comillas.

4. El "Índice" [de libros prohibidos] en la actualidad. Sal Terrae, 54, 532-534.

5. Ante la urgencia de un problema. Directrices para la pastoral de la moral íntima matrimonial. Sal Terrae, 54, 402-406.

6. Communicatio in Sacris con Protestantes y El índice de libros Prohibidos en la actualidad. Sal Terrae, 54, 528-534.

7. Apuntes de Derecho Público Eclesiástico. Madrid: ICAI-ICADE.

8. Communicatio in sacris con Protestantes y Ecumenismo. Sal Terrae, 54, 528-531.

9. El sacramento del matrimonio. Madrid: ICAI.

\section{7}

10. Sobre la libertad Religiosa. Sal Terrae, 55, 376-395.

11. Visión cristiana de la sexualidad. En $2^{\circ}$ Curso Misceláneo de Sexología (pp. 45-51). Madrid: Cruz Roja Española.

12. Guiones para el estudio de las Instituciones de Derecho Canónico. Para uso privado de los alumnos. Madrid: Universidad Pontificia Comillas. 
13. La misa dominical en la parroquia propia. Notas para el estudio de su evolución histórico-jurídica. Estudios Eclesiásticos, 42, 557-570.

\section{8}

14. La Encíclica "Humanae Vitae". Primera lectura. Razón y Fe, 177, 179-202.

15. Los transplantes de corazón y su problemática moral. Arbor, 268, 413-451.

16. Apuntes de Derecho Canónico. Madrid: Facultad de Derecho (ICADE).

\section{9}

17. Reflexiones pacíficas sobre problemas sacerdotales. Razón y Fe, 180, 187-206.

18. Derecho Canónico matrimonial. Madrid: Edic. ICAI, 122 pp.

\section{1}

19. La ley fundamental de la Iglesia. Reflexión de urgencia, Razón y Fe, 184, 61-74.

20. La ley fundamental de la Iglesia. Notas sobre una decepción. Sal Terrae, 59, 563-587.

\section{2}

21. La regulación jurídica de la Cura de almas en los canonistas hispánicos de los siglos XVI-XVII. Granada: Biblioteca Teológica Granadina, 517 pp.

22. Derecho Canónico Fundamental y Público. Madrid: Edic. ICAI, 163 pp.

\section{3}

23. Consideración moral del aborto, desde una perspectiva del valor cristiano de la vida humana. Anales de la Real Academia Nacional de Medicina, Boletín Informativo, Tomo IX, Cuaderno 2ㅜ, 235-261.

24. Todo sobre el Concordato, Revista D. Bosco en España, 348, 18-22.

25. El matrimonio meramente civil en España. Sal Terrae, 61, 568-588.

1974

26. La gravedad moral de la lujuria. Notas de teología pastoral en torno a la parvedad de materia. Sal Terrae, 62, 604-617.

27. Fórmula a de la Profesión perpetua. Sal Terrae, 62, 315-317.

28. Exención de religiosos. Sal Terrae, 62, 145-149. 
29. El consentimiento matrimonial. Problemas que plantea actualmente. Estudios Eclesiásticos, 49, 507-519.

30. La absoluta indisolubilidad del matrimonio sacramental consumado. Precisiones al tema. Sal Terrae, 62, 790-800.

31. Cremación de cadáveres. Sal Terrae, 62, 68-69.

32. Reconocimiento de hijos naturales por padres menores de edad. Sal Terrae, $62,69-70$.

\section{5}

33. La reforma del Concordato portugués en materia matrimonial. Revista Iglesia en Madrid, 34, 12.

34. Crítica al Derecho Concordatario desde una nueva comprensión de la Iglesia. Sal Terrae, 63, 31-40.

35. La Regulación canónica del matrimonio. Problemática y posibilidades. Revista Pentecostés, 13, 213-252.

36. Sanación en raíz de un matrimonio nulo por carecer de delegación el sacerdote. Sal Terrae, 63, 229-231.

37. Matrimonio meramente civil y certificado del abandono de la fe católica. Sal Terrae, 63, 70-71.

38. La renovación del Derecho de Religiosos. Revista Vida Religiosa, 157-167.

39. La regulación canónica del matrimonio. Problemática y posibilidades. Revista Pentecostés, 41-42, 227-252.

\section{6}

40. La Declaración "Persona humana" sobre la ética sexual. Lectura crítica al año de su promulgación. Razón y Fe, 194, 301-313.

41. Perspectivas de una nueva relación Iglesia-Estado en España. Sal Terrae, 64, 359-362.

42. Revisión en curso y actualización del Derecho de religiosos. Estudios Eclesiásticos, 51, 291-319.

43. El matrimonio hoy en España. Revista Crítica, 24-29.

44. La polémica televisiva sobre el divorcio. Vida Nueva, 1055, 225-261. 
1977

45. Democracia en la Iglesia. Reflexión desde el Derecho Canónico. Pastoral Misionera, marzo-abril.

46. La pastoral y el derecho ante el noviazgo. Sal Terrae, 65, 532-537.

47. Los Obispos y el matrimonio. Razón y Fe, 195, 565-567.

48. La renovación del derecho de religiosos. Notas para el balance de un decenio. Revista Confer, 16, 157-167.

49. Matrimonio canónico y matrimonio civil: previsible regulación matrimonial en ambos ordenamientos. Miscelánea Comillas, 35, 153.

50. La pastoral y el derecho ante el noviazgo y el matrimonio. Sal Terrae, 65, $532-537$.

51. El divorcio ante la ley natural, la ley canónica y la ley civil. Razón y Fe, 195, $46-57$.

52. La estabilidad del matrimonio. Lección inaugural. Madrid: Universidad Pontificia Comillas.

53. El divorcio, como mal menor. Revista Caritas, 161, 6-8.

1978

54. Las relaciones Iglesia-Estado. Revista Laicado, 36, 11-15.

55. La 10 ${ }^{a}$ Semana de Estudios y Coloquios sobre problemas teológicos actuales. Estudios Eclesiásticos, 53, 245-247.

56. Derechos y deberes de los religiosos en una sociedad sin privilegios. En VV. AA. Responsabilidades eclesiales y sociales de los religiosos (pp. 213-246). Madrid.

57. El matrimonio y la familia en la Constitución. Razón y Fe, 197, 783-787.

58. Ante el problema del divorcio. Cuadernos BAC, Madrid, 1-30.

59. Reflexiones jurídicas sobre la pastoral de las uniones irregulares. Estudios Eclesiásticos, 53, 291-320.

1979

60. Los Acuerdos Santa Sede-Estado español. Posibles claves de interpretación. Sal Terrae, 67, 53-60.

61. El Acuerdo sobre cuestiones jurídicas. Ecclesia, 1918, 84-85.

62. Notas sobre el Acuerdo Económico entre la S. Sede y el Estado español. Revista Pastoral Misionera, mayo junio, 333-336.

63. Los Acuerdos con la S. Sede (Editorial). Razón y Fe, 199, 122-124.

64. Acuerdos Iglesia-Estado en España. Notas marginales. Estudios Eclesiásticos, 54, 283-334. 
65. Sobre el futuro del matrimonio canónico en España. Razón y Fe, 200, 282-293.

66. El matrimonio canónico ante la nueva situación española. Notas para un pronóstico. Revista Iglesia Viva, 81-82, 193-206.

67. Familia y matrimonio. Respuesta cristiana a los nuevos interrogantes. Revista Communio, 3, 36-45.

68. El derecho y la pastoral ante los matrimonios irregulares. Sal Terrae, 67, 603-617.

69. Situación en la Iglesia de los católicos divorciados civilmente. Revista Misión Abierta, 2, 110-117.

\section{0}

70. Ante la reforma del Derecho matrimonial. Lectura del Proyecto en relación con el Acuerdo Jurídico entre la S. Sede y el Estado español. Razón y Fe, 201, 600-611.

71. Bibliografía en torno a los Acuerdos entre la S. Sede y el Estado español (1976-1979). Estudios Eclesiásticos, 55, 391-405.

72. Historia del texto. En Corral, C. \& Echeverría, L.(eds.), Los Acuerdos entre la Iglesia y España (pp. 79-85). Madrid: BAC.

73. Ante los proyectos de ley divorcista. Una lectura cristiana. Sal Terrae, 68, 563-576.

74. La Instrucción colectiva del episcopado español y el proyecto de la ley de divorcio. Razón y Fe, 201, 292-298.

\section{1}

75. La regulación del matrimonio canónico. En Martínez de Carvajal, J.G. \& Corral, C. (eds.), Iglesia y Estado en España (pp. 127-164). Madrid.

76. Ezkontza-zuzenbidezo egungo zenbait arazo. Januaren Deia, Urtarila Abendea, 41-65.

77. El matrimonio cristiano ante la nueva situación. Revista Communio, 3, 238-247.

78. Uniones irregulares y actitud cristiana. Razón y Fe, 204, 550-561.

79. Notas para una ética del abogado católico en las causas de divorcio civil. Razón y Fe, 204, 89-95 y en VV. AA. Curso de Derecho matrimonial y procesal canónico, vol. 5 (pp. 65-87). Salamanca.

\section{3}

80. La ley despenalizadora del aborto y su entorno. Razón y Fe, 208, 271-185.

81. Pastoral y nuevo Código de Derecho canónico. Sal Terrae, 71, 543-557. 
82. Un nuevo Código de Derecho Canónico. El Matrimonio. Ecclesia, 2115, 284-286.

\section{4}

83. Comentarios españoles al nuevo Código. Revista ICADE, 2, 207-211.

84. La nueva regulación canónica del matrimonio. Revista de legislación y jurisprudencia, 90, 335-361.

85. El estatuto de los fieles y de los laicos. Matrimonios ACIT. Madrid.

86. El nuevo derecho de religiosos. Notas previas para su comprensión. Revista Vida Religiosa, 56, 5-10.

87. El asociacionismo dentro de la Iglesia, según el nuevo Código de Derecho canónico, en Díaz Moreno, J.M. \& Echeverría, J. Mª . Genza. El asociacionismo dentro de la Iglesia. Cuestiones selectas del derecho de religiosos. Derecho patrimonial (ad usum privatum) (pp. 1-176). San Sebastián.

88. Las innovaciones de la disciplina sobre el sacramento de la penitencia en el nuevo Código. En VV. AA., Temas Fundamentales en el nuevo Código (pp. 253-292). Salamanca: Universidad Pontificia..

89. La nueva regulación del matrimonio canónico. Cuestiones preliminares. Razón y Fe, 209, 489-50.

\section{5}

90. Derecho Canónico. Apuntes Privados de la Facultad. Madrid: ICADE. (Revisados y actualizados en 1988 y 1990).

91. Cuestiones selectas del Derecho de Religiosos. en VV.AA. El asociacionismo dentro de la Iglesia. Cuestiones selectas (pp. 86-116). San Sebastián: Villa Genza.

92. La nueva regulación canónica del matrimonio. Revista Gral. de Legislación y Jurisprudencia, 90, 335-361.

93. Familia y matrimonio en el nuevo Código de Derecho Canónico. Revista ICADE, 4, 13-40.

94. Derecho matrimonial canónico. Casos prácticos. Con la colaboración de Cristina Guzmán y Teresa Mª Pérez-Agua. Madrid.

95. Los Consejos pastorales y su regulación canónica, REDC, 41, 165-182.

\section{6}

96. La mujer en la ley de la Iglesia. Revista ICADE, 9, 129-145.

97. La ley de la Iglesia y su dimensión familiar. Revista Communio, 8, 554-566. 
98. El derecho litúrgico diocesano pos-codicial. En VV.AA., Derecho particular de la Iglesia en España (pp. 153-192). Salamanca.

99. Sentido de la jurisdicción eclesial. Notas sobre los Tribunales eclesiásticos y las causas de nulidad canónica. Revista Laicado, 75, 63-72.

100. La admisión al matrimonio canónico de los cristianos que no tienen fe. En VV. AA., Consortium vitae (pp. 111-187). Salamanca.

101. Sentido de la jurisdicción eclesial. Nota sobre los Tribunales eclesiásticos y las causas de nulidad canónica. Revista Laicado, 75, 63-72.

\section{7}

102. Reflexiones sobre un conflicto. Ecclesia, 3228, 1326-1327.

103. El impedimento canónico de parentesco legal. Revista Gral. de Legislación y Jurisprudencia, 5, 793-814.

\section{8}

104. Actitud de la Iglesia en la independencia de los países de expresión española. Miscelánea Comillas, 46, 271-338 y (1989). Miscelánea Comillas, 47, 263-295 y en (1986). XX ${ }^{\underline{a}}$ Semana luso-española de Derecho Canónico, Braga 1986 (pp. 195-274). Salamanca: Publicaciones de la Universidad Pontificia de Salamanca.

105. La plena comunión con la Iglesia. Reflexiones sobre su vertiente jurídica. Communio, 10, 58-68.

106. El sistema matrimonial español en el Código Civil de 1888 . Notas sobre su entorno histórico-doctrinal. Con la colaboración de C. Guzmán y T. Mạ Pérez-Agua, Revista ICADE, 15, 65-90.

107. Remoción y traslado de párrocos. En Aznar, F.R. \& Sánchez, J. (eds.), Estudios Canónicos en homenaje al Prof. L. de Echeverría (pp. 419-440). Salamanca.

\section{9}

108. Voces: Arciprestes, Capellán, Parroquia, Remoción de Párrocos, Traslado de Párrocos, Rector de Iglesia. En Corral, C. \& Urteaga, J.M., Diccionario de Derecho Canónico. Madrid.

109. Los Acuerdos entre la S. Sede y el Estado español. Reflexión de un decenio. Razón y Fe, 219, 173-183. 
110. El asociacionismo dentro de la Iglesia. Reflexiones sobre su vertiente jurídica. En VV. AA., El laicado en la Iglesia. Salamanca: Universidad Pontificia de Salamanca y Rev. Española de D. Canónico, 46, 7-67.

1990

111. Dadaglio y las relaciones Iglesia-Estado en España. Ecclesia, 2492, 1305-1306.

112. La organización eclesiástica. Visión panorámica entre dos Códigos (1917 y 1983). Revista XX Siglos, 1, 36-46.

113. Sobre el matrimonio canónico. Tres cuestiones abiertas a la reflexión. Razón y Fe, 222, 153-169.

1991

114. De la tolerancia a la libertad religiosa. Las relaciones Iglesia-Estado en España, a través de los Editoriales de Ecclesia. Ecclesia, 2510, 49-53.

115. Derechos de los fieles y vida parroquial. En Manzanares, J. (ed.), La parroquia desde el nuevo Código de Derecho canónico (pp. 117-159). Salamanca.

116. La Iglesia y la comunidad política. El Documento de 1973. Revista XX Siglos, 2, 29-39.

117. La crisis del matrimonio. Con la colaboración de C. Guzmán y T. Ma Pérez-Agua. En Palomar, E. (ed.), El pensamiento jurídico de Castán Tobeñas (pp. 251-267). Madrid.

1992

118. La libertad Religiosa. Consideraciones desde la Declaración Conciliar y la Declaración de Derechos humanos. en Corral, C. (coord.), La libertad Religiosa hoy (VII Jornadas de Estudio. Facultad de Derecho Canónico) (pp. 15-43). Madrid: Universidad Pontifica Comillas.

119. Interrogantes éticos del matrimonio. en Vidal, M. (dir.), Conceptos fundamentales de ética religiosa (pp. 563-588). Madrid.

120. La ampliación de la ley abortista. Ecclesia, 2598, 1395-1396.

121. Vida consagrada y pastoral parroquial. Esquema a modo de respuestas. Revista Información S. J., 24, 93-109.

122. Pareja y matrimonio: diversos modelos. Actitudes cristianas ante ellas. Sal Terrae, 80, 25-38.

123. Familias en conflicto. Perspectivas pastorales ante situaciones difíciles e irregulares. En CEAS de la C. E. Española (pp. 213-276). Madrid. 
124. La fe cristiana ante los retos culturales de un nuevo siglo. Razón y Fe, 226, 100-106.

1993

125. Las relaciones entre la Iglesia y la comunidad política. Cuadrón, A. (coord.), Manual de Doctrina Social de la Iglesia (pp. 717-738). Madrid.

126. La Iglesia particular y vida consagrada. Revista Catalana de Teología, 18, 247-260.

127. Los XXV años de la Encíclica "Humanae Vitae". Revista XX Siglos, 4, 21-33.

128. Los derechos humanos en la Iglesia. Aula de Cultura de El Correo Español-El Pueblo vasco, 12, 227-254.

129. La Eucaristía en la regulación canónica de la cura de almas, según los canonistas hispánicos de los siglos XVI-XVII. En Castañeda, P. y Martínez de la Hoz, J.C., Eucaristía y nueva evangelización (pp. 49-59). Sevilla.

130. El fracaso matrimonial. Soluciones canónicas. En VV. AA., Políticas de la Familia (pp. 649-659). Madrid.

131. El fracaso matrimonial. Soluciones canónicas. Revista ICADE, 28, 517.

132. Introducción a la Segunda Parte de las Constituciones de la Compañía de Jesús. En Arzubialde, S., Corella, J. \& García-Lomas, J.M. (eds.), Las Constituciones de la Compañía de Jesús (pp. 117-124). Bilbao.

133. José $\mathrm{M}^{\mathrm{a}}$ Díaz Moreno, jesuita por vocación y jurista por obligación. Glasnost. Revista de alumnos ICADE, 1, 13-16.

\section{4}

134. Los sacramentos como derecho del fiel. En Melero, C. (ed.), Derecho Canónico a los diez años de la promulgación del Código (pp. 117-166). Salamanca.

135. La Iglesia ante las familias de hecho y monoparentales. En VV. AA., La familia en un mundo cambiante (pp. 271-293). Salamanca: Universidad Pontificia de Salamanca.

136. Fe y sacramento del matrimonio de los bautizados, según jurisprudencia reciente. En Curso de Derecho Matrimonial y procesal canónico para profesionales del foro, XI (pp. 55-105). Salamanca.

137. La relación fe-sacramento y la validez-nulidad matrimonial. En VV. AA., lus in vita et missione Ecclesiae (pp. 1103-1116). Cittá del Vaticano.

138. El abandono de la Iglesia católica y su incidencia en el derecho matrimonial canónico. En Aznar Gil, F.R. (ed.), Magister canonistarum (pp. 141-157). Salamanca.

139. Situaciones irregulares en la familia. Revista Moralia, 17, 379-418.

140. Los derechos humanos en la Iglesia. Revista Comunicació, 79, 31-56. 
141. El Estatuto canónico de la familia. Interrogantes. Carencias. Posibilidades. Revista ICADE, 34, 113-130.

142. La familia entre o pasado e o futuro. En Libro de relatoiros do Congreso Internacional da Familia (pp. 423-441). Santiago de Compostela.

143. D. Vicente, nuestro Cardenal. Razón y Fe, 231, 91-98.

1996

144. La tolerancia religiosa en el Derecho Constitucional contemporáneo. En VV.AA., Tolerancia y fe católica en España (pp. 35-74). Salamanca.

145. Ley civil y conciencia moral en la "Evangelium vitae". Revista Moralia, 19, 33-52.

146. Pablo VI y las relaciones Iglesia-Estado en España. Notas sobre un decenio (1968-1978). En VV. AA., Pablo VI y España (pp. 50-54). Brescia.

147. El Derecho Canónico a los diez años de la promulgación del Código. Anuario de Derecho Eclesiástico del Estado, 12, 927-933.

148. San Ignacio y la ley. Reflexiones sobre la actualización y renovación del Derecho de la Compañía de Jesús. Revista Manresa, 68, 133-160.

149. La familia cristiana. La lección del pasado y la previsión del futuro. En Rodríguez Torrente, J. (ed.), Familia y política. Controversias y futuro (pp. 41-62). Madrid.

150. Católicos en la Vida pública. Hacia una nueva estructuración del Derecho Público Eclesiástico. Lección Inaugural. Madrid: Universidad Pontificia Comillas, 68 pp. (El mismo estudio en México: Publicaciones de la Universidad Pontificia, 1997).

151. Profesores y tutores que atiendan con solvencia las consecuencias de los conflictos conyugales. Ecclesia, 2085, 14-15.

152. La ley civil y conciencia moral en la "Evangelium vitae". Revista Moralia, 19, 33-52.

153. Pablo VI y las relaciones Iglesia-Estado en España. Notas sobre un decenio (1968-1978). En VV. AA., Pablo VI y España (pp. 50-54). Brescia.

1997

154. El Derecho canónico ante el matrimonio de los deficientes mentales. En VV. AA., Matrimonio y deficiencia mental (pp. 171-209). Madrid.

155. La Iglesia y el poder político. Consideración desde el Derecho Público Eclesiástico. En Castañeda, P. y Concina y Abella, M.J. (coords.), Iglesia y poder público (pp. 45-59). Córdoba. 
156. Los católicos y las familias de hecho. Ecclesia, 2848, 986-987.

157. Las familias de hecho. Aproximación a su vertiente jurídica. Razón y Fe, 236, 33-54.

158. Las familias de hecho y monoparentales. Problemática plural ante el tercer milenio. En Del Río, J. (ed.), Desafíos de final de siglo (pp. 267-294). Sevilla.

\section{8}

159. La corrupción de menores y la ética cristiana ¿una vertiente olvidada del pecado social? En Rodríguez Torrente, J. (dir.), El menor y la familia: conflictos e implicaciones (pp. 209-225). Madrid.

160. El gobierno de la parroquia. En VV.AA., Aspectos de la función de gobierno (pp. 165-211). Salamanca.

161. Reconocimiento y vigencia de los derechos humanos en la Iglesia. Revista ICADE, 44, 53-75.

162. Reflexiones pacíficas sobre la crisis sacerdotal del posconcilio. Revista XX Siglos, 9, 16-28.

163. Celebración del matrimonio canónico con no bautizados. Problemática en el derecho sustantivo. En Rucosa Escudé, A. (ed.), Matrimonio canónico. Problemas en su celebración y disolución (pp. 85-125). Salamanca.

1999

164. Direito dos fiéis a os sacramentos e auxilios spirituais. En VV. AA., Devere e direitos dos fiéis na lgreja (pp. 51-85). Lisboa.

165. La vertiente pastoral del abandono notorio de la de la fe (can.1071, párrafo $1^{\circ}, 4^{\circ}$ ) y del apartarse de la Iglesia por un acto formal (can. 1117). En Estudios de homenaje al Dr. D. Juan L. Acebal (pp. 39-52). Salamanca.

166. La trasmisión de la foi au sein de la famille. En Chantal Rodet, La transmisión dans la famille (pp. 371-380). París.

167. Los matrimonios fracasados. Vertiente canónica y pastoral. En Jornadas sobre la familia (pp. 76-91). Madrid.

168. Actitud cristiana ante los divorciados. Anotaciones personales. Sal Terrae, 99, 543-553.

169. El Derecho Canónico de Código a Código. Balance de un siglo. Revista ICADE, 46, 37-49.

170. Las familias de hecho. Aproximación a su vertiente ético-canónica. En VV. AA., Las uniones de hecho. Una aproximación plural, Instituto de la familia (pp. 99-116). Madrid: UPCO. 
171. Enseñanza de ciencias sagradas y Magisterio. En Escritos en honor de Javier Hervada, lus Canonicum, 44, 313-324.

172. La problemática del Derecho Procesal matrimonial en dos obras recientes. Estudios Eclesiásticos, 74, 883-889.

173. Notas marginales sobre la teología moral sexual en el pensamiento de Bernhard Häring. Estudios Eclesiásticos, 74, 493-512.

174. El Derecho Canónico en Estudios Eclesiásticos. Estudios Eclesiásticos, 74, 621-638.

2000

175. Principios informadores de los Acuerdos entre la Iglesia Católica y las Comunidades autónomas. En colaboración con la Pof ${ }^{a}$. Cristina Guzmán Pérez. En VV. AA., Estudios en homenaje al Prf. J. Martínez Valls, vol. 1, (pp. 167-180). Alicante: Universidad de Alicante.

176. Matrimonio de los católicos que han abandonado la Iglesia católica por un acto formal. En Aznar Gil, F. (ed.), Curso de Derecho matrimonial y procesal canónico para profesionales del foro (pp. 15-38). Salamanca.

177. Dificultades en el matrimonio. Revista Diálogo, 225, 7-19.

178. La trasmisión de la fe en la familia. Un reto en el siglo XXI. Revista Almogaren, 27, 109-120.

179. Paz en el matrimonio. Sal Terrae, 88, 231-241.

180. Los divorciados vueltos a casar. Revista Vida Nueva, 2.242, 21-32.

181. Nuevas situaciones morales en la familia. Revista Diálogo Familia-Colegio, 218, 3-10.

182. Derecho Canónico. Parte General y Derecho matrimonial, $2^{\underline{a}}$ edic. en colaboración con la Prof ${ }^{\mathrm{a}}$. Dra. Cristina Guzmán Pérez. Madrid: ICADE-Universidad Pontificia Comillas, 707 pp.

\section{1}

183. Principios teológico-canónicos reguladores de la organización de la Curia Diocesana. En Aznar Gil, F. (ed.), La Curia Diocesana: la función administrativa (pp. 11-50). Salamanca.

184. La naturaleza pública de las Hermandades y Cofradías en una resolución y Decreto del Consejo Pontificio para los laicos. Estudios Eclesiásticos, 76, 133-138.

185. Las relaciones Iglesia-Estado en la segunda mitad del siglo XX. Datos personales para un balance. Revista XX Siglos, 12, 58-77. 
186. Los fundamentos teológicos del Derecho Canónico, Estudios Eclesiásticos, 76, 115-126.

187. El Tribunal Eclesiástico y la Iglesia diocesana, en Aznar Gil, F. (coord.), La administración de la justicia eclesiástica en España (pp. 213-242). Salamanca.

188. El dinero de la Iglesia y en la Iglesia. A propósito del asunto Gescartera. Revista RS, 837, 36-37.

2002

189. Actualidad de una vieja institución eclesial. $\chi X$ Siglos, 5-15.

190. Fundamentos teológicos y requisitos canónicos de la función consultiva en la Curia diocesana. En San José Prisco, J. (coord.), La curia diocesana: la función consultiva (pp. 33-58). Salamanca.

191. El escándalo y su sombra. Razón y Fe, 245, 129-148.

192. Un Derecho Universitario del siglo XVII. En "Iuri Canonico quo sit Ecclesia felix", Estudios en homenaje al Prof. Dr. J. Manzanares (pp. 77-100). Salamanca.

193. Nota sobre el modo humano del can. 1061, párr. 1 y la inseminación artificial homóloga. en Ferrer, J. \& Martínez, J. (ed.), Bioética. Un diálogo plural. Homenaje al P. J. Gafo (pp. 717-732). Madrid.

194. Actualidad canónica. Notas sobre cuatro monografías. Estudios Eclesiásticos, 77, 661-669.

195. Las relaciones Iglesia-Estado en España. Datos para un balance. Revista Forum iuridicum, 1, 171-206.

2003

196. Notas bibliográficas sobre la aportación española al estudio de la Libertad Religiosa (1965-1970). En Estado y sociedad internacional. Homenaje a D. José Giménez Martínez de Carvajal (pp. 75-104). Madrid.

197. Sociedad pluralista, Estado aconfesional, libertad religiosa. Tres ejes fundamentales de la Constitución española ante el hecho religioso. Revista ICADE, 58, 29-50.

198. La Iglesia no puede vivir sin un ordenamiento jurídico. Revista Alfa y Omega,18-19.

\section{4}

199. Antecedentes del can. 1095 en la doctrina y jurisprudencia española. en Cortés, M. (coord.), Curso de Derecho matrimonial y procesal canónico (pp. 17-68). Salamanca. 
200. El matrimonio meramente civil de los católicos. Algunas precisiones. Razón y Fe, 249, 157-168.

201. Nuestros libros. Estudios Eclesiásticos, 79, 729-740.

202. Afectividad y sexualidad de las personas con discapacidad. Anotaciones desde el Derecho matrimonial canónico. En Adroher, S. (coord.), Discapacidad e integración en la familia, trabajo y sociedad (pp. 51-57). Madrid.

203. P. José Luis de Urrutia Sasiain, S.J. Semblanza. Estudios Eclesiásticos, 79, 741-742.

204. La regulación codicial de los sacramentos de la iniciación cristiana y su problemática pastoral. En Pérez Ramos, A. (coord.), XXIII Jornadas de la Asociación española de canonistas (pp. 11-50). Madrid.

205. La transmisión de la fe en la familia. Revista Diálogo, 247, 3-11.

206. Presentación de la Tierra sin mal de Jesús Sánchez Adalid. Revista Anales ICAI, 81, 73-76.

207. iEl matrimonio civil es inexistente para la Iglesia? Revista RS, 862, 35-38.

208. El pluralismo religioso en la familia. Revista Diálogo, 248,17-23.

209. Il matrimonio civile dei cattolici. La Civiltà Cattolica, 155, 242-251.

2005

210. Los Acuerdos entre la Santa Sede y el Estado Español de 1979. Revista Moralia, 28, 475-502.

211. Relevancia canónica del matrimonio meramente civil de los católicos. En San José Prisco, J. \& Cortés, M., Curso de Derecho matrimonial y procesal Canónico para profesionales del foro (pp. 13-40). Salamanca.

212. D. Andrés Manjón, un canonista olvidado. En Rivas, F. \& Sanz de Diego, R., Homenaje a Juan $M^{\underline{a}}$ Laboa (pp. 397-434). Madrid.

213. Las relaciones Iglesia-Estado. De la unión a la mutua independencia y colaboración. Revista Corintios XIII, 116, 175-220.

214. Un caso de disolución del vínculo matrimonial in favorem fidei. Aplicación del can. 1150 en la duda de hecho. Estudios Eclesiásticos, 80, 855-869.

215. El precepto dominical. Reflexión desde el derecho canónico. Revista Forum iuridicum, 4, 127-148.

2006

216. El proceso de negociación y conclusión de los Acuerdos entre la S. Sede y el Estado español de 1979. En VV. AA., Laicidad Cristiana e identidad cristiana (pp. 13-48). Salamanca. 
217. Matrimonios no-canónicos y competencia de los Tribunales eclesiásticos. En XXVI Jornadas de la Asociación española de canonistas (pp. 83-117). Madrid.

218. El derecho a la intimidad (pp. 555-583). Berlín: Duncker-Humblot.

2007

219. Matrimonios no canónicos y competencia de los Tribunales Eclesiásticos. En Rodríguez Chacón, R. (coord.), Temas candentes de Derecho matrimonial y procesal y en las relaciones Iglesia - Estado (pp. 13-48). Madrid.

220. La corta duración del matrimonio, como indicio de nulidad. En San José Prisco, J. \& Cortés, M., Curso de Derecho matrimonial y procesal canónico para profesionales del foro (pp. 467-486). Salamanca.

2008

221. Lectura canónico-pastoral del Sínodo de los Obispos sobre la Eucaristía, REDC, 65, 493-515.

222. Antonio Quintana Dueñas, S. J., (1599-1651). Apuntes para la semblanza de un canonista extremeño. Revista Cauriensia, 3, 319-333.

223. Una peculiar y significativa visión católica de Concepción Arenal. Notas sobre dos estudios del P. Julio Alarcón Meléndez, S. J. Miscelánea Comillas, 66, 349-380.

2009

224. Los Derechos Humanos en el Código de Derecho Canónico. Miscelánea Comillas, 67, 53-73.

225. El P. Luis Vela Sánchez, S. J. En Peña García, C., Personalismo jurídico y derecho canónico. Estudios jurídicos en homenaje al P. Luis Vela, S. J. (pp. 1940). Madrid.

2010

226. La Constitución Quot Anglicanorum coetibus, sobre los ordinariatos personales para los anglicanos que ingresan en la plena comunión con la Iglesia. REDC, 67, 401-436.

227. Mirando hacia atrás sin ira y con cierta nostalgia en homenaje al P. Vela, S. J. Estudios Eclesiásticos, 85, 871-878.

228. El principio de totalidad y su aplicación. Una notable aportación del P. Adolfo Fernández Díaz-Nava, S. J. Miscelánea Comillas, 68, 53-68. 
229. Anotaciones personales sobre el "Servicio de orientación jurídica". En Otaduy, J. (coord.), XXIX Jornadas de actualidad canónica (pp. 191-208). Madrid.

230. Por qué y cómo se hicieron los Acuerdos entre España y la S. Sede. En Caparrós, M.C., Martín, M.M. \& Salido, M. (eds.) XXX años de los Acuerdos entre España y la S. Sede (pp. 21-50). Granada: Edit. Comares.

\section{1}

231. Nuevos problemas morales en la familia. Cercanía cristiana a las familias rotas. En Berástegui Pedro-Viejo, A. \& Gómez Bengoechea, B., Horizontes de la familia ante el siglo XXI (pp. 63-88). Madrid.

232. Incunable. Notas sobre un olvidado Periódico sacerdotal, fiel testigo de su tiempo. Miscelánea Comillas, 69, 413-441.

233. Semblanza del Cardenal Urbano Navarrete, S. J. Estudios Eclesiásticos, 86, 825-828.

\section{2}

234. Estanislao Olivares D'Angelo, S. J. Un jesuita sevillano y canonista granadino. Estudios Eclesiásticos, 87, 867-872 y Proyección, 245, 195-202.

\section{3}

235. Los diez primeros informes sobre la revisión el Concordato de 1953. Contribución a la historia de los Acuerdos vigentes. REDC, 70, 143-158 y en Martínez-Torrón, J., Meseguer, S. \& Palomino, R. (coords.), Religión, Matrimonio y Derecho, ante el siglo XXI. Estudios en homenaje al Prof. Rafael Navarro-Valls (pp. 187-203). Madrid.

236. Las negociaciones concordatarias y la transición política española. Estudios Eclesiásticos, 88, 936-937.

237. La función de enseñar en el derecho y en la vida de la Iglesia. Estudios Eclesiáticos, 88, 927-930.

238. El vol. XI del Synodicum hispanum. Estudios Eclesiásticos, 88, 931-933.

239. El Rey, la Iglesia y la Tradición. Estudios Eclesiásticos, 88, 937-941.

\section{4}

240. Divorcio y divorciados. Reflexión ante el Sínodo de la familia. Razón y Fe, 270, 437-440. 
241. El Sínodo de la familia. Algunas cuestiones abiertas. Estudios Eclesiásticos, 89, 767-780.

242. El Derecho de la Iglesia. Los Códigos de 1917 y 1983. En Escudero, J.A., La Iglesia en la historia de España (pp. 1349-1357). Madrid.

243. El Derecho Canónico entre dos códigos. En Sánchez Girón Renedo, J.L. \& Peña García, C. (coords), El Código de Derecho Canónico: balance y perspectivas (pp. 23-34). Madrid.

244. Matrimonio y causas de nulidad en el Derecho de la Iglesia. Estudios Eclesiásticos, 89, 836-340.

\section{5}

245. El Sínodo sobre la familia (2014). Una lectura desde el Código de Derecho Canónico. En VV. AA., Pasture les mes ovelle (Jn 21, 16). Miscel.Lánia d'Homenatge al Cardenal Lluis Martínez Sistach (pp. 765-782). Barcelona.

246. El Sínodo de la familia. Notas marginales. Estudios Eclesiásticos, 90, 751-764.

2016

247. El sacramento del perdón. Anotaciones canónico-pastorales. REDC, 73, $87-106$.

248. Conversaciones con Marciano Vidal. Revista ICADE, 97, 167-169.

249. Mirando hacia atrás. Razón y Fe, 274, 311-322.

\section{7}

250. Las relaciones Iglesia-Estado en España, en la segunda mitad del siglo XX. Notas personales. En Moreno Antón, M., Sociedad, Derecho y Factor religioso. Estudios en honor del Prof. Isidoro Martín Sánchez (pp. 195-210). Granada.

\section{9}

251. La intimidad de la persona como derecho fundamental. Una reflexión en torno a los can. 220 y 642 en. I. E. Lázaro y A. Serrano (directores). Estudios Jurídicos en homenaje al Profesor Don José Mํ Castán Vázquez (pp. 211-226). Madrid: Edit. Reus y Universidad Pontificia Comillas. 